\title{
An assessment of the quality of advice provided by patent medicine vendors to users of oral contraceptive pills in urban Nigeria
}

This article was published in the following Dove Press journal:

Journal of Multidisciplinary Healthcare

8 April 2014

Number of times this article has been viewed

\author{
Chinazo Ujuju' \\ Samson B Adebayo ${ }^{2}$ \\ Jennifer Anyanti ${ }^{3}$ \\ Obi Oluigbo ${ }^{3}$ \\ Fatima Muhammad ${ }^{4}$ \\ Augustine Ankomah ${ }^{5}$ \\ 'Research and Evaluation Division, \\ Society for Family Health, Abuja, \\ Nigeria; ${ }^{2}$ Planning, Research and \\ Statistics Directorate, National \\ Agency for Food and Drug \\ Administration and Control, \\ Abuja, Nigeria; ${ }^{3}$ Technical Services \\ Directorate, Society for Family \\ Health, Abuja, Nigeria; ${ }^{4}$ Family \\ Planning Directorate, Society \\ for Family Health, Abuja, Nigeria; \\ ${ }^{5}$ Department of Population, Family \\ and Reproductive Health, School of \\ Public Health, University of Ghana, \\ Legon, Accra, Ghana
}

Introduction: In Nigeria about $50 \%$ of oral contraceptive pill users obtain their products from proprietary patent medicine vendors (PPMVs). This group of service providers are poorly trained and have very limited knowledge about contraception. This paper investigated the nature of the advice offered to simulated current and potential users of oral contraceptive pills. The main objective was to assess the nature and quality of advice provided by PPMVs to pill users.

Method: This study is based on findings from a 'mystery client' approach in which three scenarios related to contraceptive pill use were simulated. Each of the 12 mystery clients simulated one of the following three scenarios: new pill users (new to family planning or switching from condom to pills); user seeking a resupply of pills; and dissatisfied pill users intending to discontinue use. Simple random sampling was used to select 410 PPMVs from a total of 1,826 in four states in Nigeria. Qualitative study using in-depth interviews was also conducted.

Results: A majority of the PPMVs had pills in stock on the day of the survey and resupplied pills to the clients. PPMVs also understood the reason and importance of referring clients who were new adopters of oral contraceptive methods to a health facility; $30 \%$ of the PPMVs referred new adopters to a health facility. However, demand from clients who do not want to go to health care facilities (for various reasons) necessitated the provision of oral contraceptive pills to $41 \%$ of the first time users. Some PPMVs prescribed treatment to mystery clients who presented with perceived complications arising from the use of pills, while $49 \%$ were referred to a health facility.

Conclusion: The advice given by PPMVs often falls short of safety guidelines related to the use of oral contraceptive pills. There is a need to continuously update knowledge among the PPMVs to ensure that they provide quality oral contraceptive services as PPMVs bridge the gap between medical experts and users in rural communities.

Keywords: oral contraceptive pills, contraceptives, patent medicine vendors, mystery client, PPMV, quality of care, Nigeria

\section{Introduction}

Improving availability and access to modern contraceptives in rural and suburban communities in developing countries is one method of ensuring contraceptive security and increasing contraceptive uptake. Contraceptive security exists when every person is able to choose, obtain, and use quality contraceptives and other reproductive health products when and where they need them, regardless of wealth, geographical location, and ethnic group. ${ }^{1}$ The shortage of health care facilities and providers in rural and suburban communities limits the availability and access to essential health care products and services, including contraceptive products. In many rural and urban areas in Sub-Saharan Africa, health care services are often provided by proprietary patent
Correspondence: Augustine Ankomah Department of Population, Family and Reproductive Health, School of Public Health, University of Ghana, Legon, Accra, Ghana

Tel $+23326 I 524407$

$\mathrm{Fax}+233302512504$

Email augankomah@gmail.com 
medicine vendors (PPMVs). PPMVs are a large group of informal health providers who often operate from a shop and are patronized by all segments of the community, especially the poor. ${ }^{2}$ The roles of PPMVs have long been recognized and reported in several countries in Sub-Saharan Africa, including Kenya ${ }^{3}$ and Cameroon. ${ }^{4}$ Informal health care providers comprise a significant component of health systems in developing nations, yet little is known about their most basic characteristics in terms of performance and quality. In a recent systematic review on the role of the informal health care providers in developing countries, it was found that adherence to national guidelines by informal health service providers is lacking and provider practices are poor. ${ }^{5}$

Unlike retail pharmacies who must list a registered pharmacist as at least one of the owners, PPMVs in Nigeria are not required to have a pharmacist attached to the business. ${ }^{6}$ In 2006, there were 13,903 PPMVs registered with the Pharmaceutical Council of Nigeria (PCN), ${ }^{6}$ but this is certainly an underestimate given that many PPMVs are not registered with the PCN. One estimate puts the number of PPMVs in Nigeria as high as 43,000. ${ }^{7}$ In Nigeria, a PPMV or "patent medicine seller" can be defined as a person without formal pharmacy training who sells orthodox pharmaceutical products on a retail basis for profit. ${ }^{8}$ PPMVs are the primary source of drugs in many suburban and rural communities as they are found in both rural and urban communities in Nigeria. ${ }^{9}$ In Nigeria, PPMVs are noted for dealing in a variety of medicines and services. They are authorized to sell overthe-counter drugs including common drugs such as pain killers, cough syrups, and antimalarials. ${ }^{10}$ Several studies have reported PPMVs as the most common source of malaria treatment in Nigeria. ${ }^{2,11-14}$ They are also reported to offer treatment of childhood diarrhea ${ }^{9}$ as well as hypertension. ${ }^{15}$ Originally meant to sell only over-the-counter and nonprescription medications, the role of PPMVs has evolved to include the sale of prescription medications for multiple diseases ${ }^{16-17}$ today they generally sell all types of drugs as determined by their financial capability. ${ }^{10}$

A majority of the PPMVs are without a medical background; some of them having only a primary level of education, while most lack adequate knowledge of how to dispense oral contraceptives and the skills to communicate key information to potential users. Some PPMVs start as apprentices to acquire skills under an existing license holder. ${ }^{18-20}$ Others may be former or current auxiliary level health staff. ${ }^{18,20,21}$ It is therefore necessary to provide PPMVs with adequate training on the use of contraceptive methods with the aim of enhancing their counseling skills and implementing best dis- pensing practices. Findings from previous studies in Nigeria recommended improving the knowledge of PPMVs in drug dispensation through training, as done in other countries, such as $\mathrm{Nepal}^{22}$ and Kenya. ${ }^{23}$

The form of advice provided by PPMVs has been reported in an earlier study. ${ }^{22}$ In recent years, studies have reported on the quality of advice provided by PPMVs in universal precautions $^{24}$ and in treatment of childhood diarrhea ${ }^{9}$ and malaria. ${ }^{2,13,14}$

Three-fifths of users of contraceptives obtain their contraceptives from the private medical sector, and about half of oral contraceptive pill users get their supply from PPMVs. ${ }^{25}$ In Nigeria, PPMV shops are the common place to purchase contraceptives for over 60 million persons of reproductive age ${ }^{26}$ very little is known about the nature and quality of the advice on contraceptive use provided by PPMV shop attendants to their clients. Given that PPMVs generally have no formal pharmaceutical training, the national family planning reproductive health guidelines and standards of practice allow PPMVs to sell oral contraceptives for refill and refer first-time oral contraceptive users to a qualified provider. ${ }^{27}$ However, little is known about how PPMVs adhere to the guidelines. This paper reports on the nature of the advice provided by PPMVs specifically related to the prescription and sale of oral contraceptive pills, in particular their referral practices and resupply practices. Using the mystery client approach, this paper assesses whether PPMVs follow statutory prescription practices related to counselling, referral to higher level of care, and resupply of contraceptives. The study also assessed whether PPMVs can identify side effects of oral contraceptive pills and take appropriate action, as well as the challenges faced by PPMVs when providing family planning services in their communities. Findings from this paper will provide information for government- and donor-driven programs to develop interventions that will improve the quality standards of PPMVs in Nigeria. Similar programs have been developed and implemented in Tanzania through the Accredited Drug Dispensing Outlet (ADDO) national rollout strategy. ${ }^{28}$

\section{Methods and materials}

In this study, the mystery client approach was employed. It is an approach that uses simulated clients to assess the reception and services provided by service providers. As used in this study, the mystery client approach presented a woman (a simulated client) of reproductive age who visited a PPMV anonymously, posing as a customer/client with the intention of demanding and obtaining a contraceptive method. After leaving the facility, the mystery client completed a 
form detailing the advice received at the outlet. During each visit, each mystery client was to simulate one of the following three scenarios: a client who had never used family planning demanding the use of oral contraceptive pills; a client desiring resupply of oral contraceptive pills; and a dissatisfied user of oral contraceptive pills wanting to switch to any other method. The mystery clients involved in the study were aged 24 to 27 years and were recruited from different communities outside of the study locations. A total of 12 mystery clients and four supervisors took part in the study.

A total of 410 PPMVs selling contraceptive pills in Lagos, Enugu, Kano, and Plateau states were selected for the survey. The sampling frame for the selection of the outlets was an updated list of 1,826 PPMVs obtained from local PPMV associations compiled by the researchers. We ensured that PPMVs that had ceased operating or relocated outside the city were removed from the list. The 410 PPMVs were selected in proportion to the number listed for each of the four states as follows: 240 of 1,099 in Lagos state; 88 of 364 in Enugu state; 50 of 230 in Plateau state; and 32 of 133 in Kano state. A simple random sampling was used to select the PPMV outlets for participation in the study.

During the data collection, each mystery client visited between six to eight PPMV outlets per day and presented one of the following scenarios: first time user of pills intending to adopt a method; a dissatisfied pill user intending to switch to any other method; or a user looking for a resupply of pills. After leaving the facility, the mystery client filled out a survey form detailing the service and experience at the outlet. At the end of each day, the team met to debrief and ensure that the study was on track.

The mystery clients were trained for 3 days prior to the fieldwork to acquaint them with all issues related to the survey methodology and instruments. As part of the training, detailed information about the oral contraceptive pill was provided and discussed. This included contraindications, side effects, and complications that may be associated with oral contraceptive pills. Also discussed were, when and how to take the oral contraceptive pills and what to do in case a woman missed a pill. Using role playing and other practical sessions, participants were also trained on how to simulate the three scenarios. The training ensured that each mystery client developed and demonstrated competence in the particular scenarios they were to simulate in the field. Dissatisfied users wanting to switch methods were trained in how to present with at least one of the following simulated complications: severe headache, irregular menstruation, breast pain, nausea, abdominal pain, blurred vision, and weight gain. They were also instructed not to accept any treatment offered, apart from the purchase of pills.

The authors attended the meetings of local PPMV associations and briefed them about the study. Many PPMVs in Nigeria trade in products they are not authorized by law to stock. Insisting on written conformed consent would have created suspicion and outright refusal to participate; we therefore obtained verbal informed consent from members of each association. However, given that mystery clients were used, the exact time and the PPMVs that were to be visited by mystery clients were not disclosed.

A qualitative study using in-depth interviews (IDIs) was also conducted to obtain information from PPMVs on some objectives of the study that could not be captured with the mystery client survey. Issues, such as whether PPMVs find it convenient to refer new family planning clients to a health facility and the challenges PPMVs face when providing family planning services in their communities, were explored. Two IDIs were conducted in each location. A total of eight IDIs were conducted during the study.

\section{Data analysis}

Quantitative data were managed and analyzed with Statistical Package for Social Sciences Version 16 (IBM Corporation, Armonk, NY, USA) based on a predetermined analysis plan. Because some cells had expected values below 5.0, analyses were based on Fisher's exact tests. Qualitative data generated from IDIs with some PPMV owners were also analyzed using transcript-based analysis.

\section{Results}

A total of 410 PPMVs were sampled from the list of PPMV outlets. The sample was proportionally allocated according to the total number of PPMVs trained across the states. Table 1 presents findings on descriptive information about the study. Almost three-fifths (58.5\%) of PPMVs were sampled in Lagos, about one-fifth (21.5\%) in Enugu, about one-tenth $(12.2 \%)$ in Plateau, and less than one-tenth (7.8\%) in Kano state. Ninety-four (94) percent of the outlets visited were in urban and semiurban areas while only $6 \%$ were in rural areas. Clients were asked to note the nature and form of any procedures or formalities they had to go through before they could see a PPMV at the outlet. More than four-fifths (82\%) of the clients did not have to go through any formality at the outlet. Only $17 \%$ of the clients had to wait or queue at the outlet before being attended to. Similarly, nine-tenths (91\%) of the mystery clients reported they were received in a friendly manner at the outlet. Approximately $77 \%$ of the 
Table I Descriptive information about the background characteristics of outlets and clients

\begin{tabular}{lll}
\hline Characteristics & $\%$ & Total $\mathbf{( N )}$ \\
\hline Outlet characteristics & 21.5 & 88 \\
$\quad$ Enugu & 58.5 & 240 \\
Lagos & 7.8 & 32 \\
$\quad$ Kano & 12.2 & 50 \\
$\quad$ Plateau & & \\
Locality & 94.0 & 375 \\
$\quad$ Urban & 6.0 & 24 \\
$\quad$ Rural & & \\
Service personnel characteristics & & \\
Sex of the service personnel & 66.6 & 269 \\
$\quad$ Male & 33.4 & 135 \\
$\quad$ Female & 79.3 & 321 \\
Service personnel & 20.5 & 83 \\
$\quad$ PPMV owner & 0.2 & 1.0 \\
PPMV attendant & & \\
$\quad$ Nurse & 44.9 & 184 \\
Enacted scenario & & \\
$\quad$ New pill users (new to family planning & 19.8 & 81 \\
$\quad$ or switching from condoms to pills) & 35.4 & 145 \\
$\quad$ Resupply & & \\
$\quad$ Dissatisfied pill users or wanting to switch \\
from pills to another method
\end{tabular}

Abbreviation: PPMV, proprietary patent medicine vendor.

mystery clients reported the time spent with service personnel as adequate.

Findings are presented based on the three scenarios enacted by the mystery clients at the facilities.

\section{First time users of the oral contraceptive pill}

By law PPMVs are not authorized to provide oral contraceptive pills for first time users as many are not professionally qualified to be able to identify contraindications. Clients who presented desiring to use oral contraceptive pills for the first time reported that $30 \%$ of the PPMVs referred them to nearby clinics or hospitals for medical checkups or asked them to see a doctor (Table 2). Quite importantly, $41 \%$ prescribed daily oral contraceptive pills to the clients while $9 \%$ actually sold oral contraceptive pills to the clients. Of all the simulated new oral contraceptive pill users, only $24 \%$ reported they were
Table 2 Assessment of advice provided by PPMVs to different clients

\begin{tabular}{|c|c|c|}
\hline & $\%$ & Total (N) \\
\hline \multicolumn{3}{|l|}{ New pill users $(\mathrm{N}=184)$} \\
\hline Prescribed or sold pills & 40.8 & 75 \\
\hline Referred to higher level & 30.4 & 56 \\
\hline Advised on what to do when they miss a pill & 23.9 & 44 \\
\hline Asked if ever used any method of contraception & 32.1 & 59 \\
\hline Possible side effects mentioned & 15.2 & 28 \\
\hline Advised on how to manage side effects & 7.6 & 14 \\
\hline \multicolumn{3}{|c|}{ Dissatisfied users wanting to switch method $(\mathrm{N}=\mid 45)$} \\
\hline Advised or referred client to seek medical help & 49.0 & 71 \\
\hline Change method of contraception with no further & 79.3 & 115 \\
\hline action PPMV prescribes treatment & 9.7 & 14 \\
\hline \multicolumn{3}{|l|}{ Resupply (N=8I) } \\
\hline Sold pills with no questions asked & 60.5 & 49 \\
\hline
\end{tabular}

Abbreviation: PPMV, proprietary patent medicine vendor.

informed of what to do if they missed a pill and 13\% were informed of the importance of taking the seven iron tablets in the 28 pill pack. Furthermore, only 15\% were informed of any possible side effects of the pills. A major aspect of counseling clients who want to use oral contraceptive pills is how to manage side effects, yet only $8 \%$ of the PPMVs explained to the clients how to manage possible side effects if they occurred. The study sought to find whether there were differences in advice provided by PPMV owners and those provided by attendants who were not owners. As shown in Table 3, there were no significant differences between owners and attendants in all of the areas they were expected to offer advice on, including prescription, referral, and management of side effects. Similarly, as shown in Table 3, with the exception of only one piece of advice, there were no differences between the advice offered by male and female service providers. Advising new pill users on what to do when they miss a pill, however, differed between males and females. While over one-quarter $(26.7 \%)$ of male service providers advised properly on what to do when new pill users missed a pill, none of the female service providers did so $(P<0.05)$. Regarding the language used in the interactions, Table 3 shows that $49.1 \%$ of interactions in English resulted in the sale of oral contraceptive pills to new users compared with $23.0 \%$ who used local languages $(P<0.05)$. On all other aspects, however, the advice given to new users in English was not significantly different from that given in other local languages.

\section{Dissatisfied pill users wanting to switch to any other method}

Dissatisfied pill-users and clients who wanted to switch from oral contraceptive pills presented at least two or more predetermined complications. Complications presented 
Table 3 Assessment of advice provided to simulated new contraceptive pill users according to type of PPMV (based on Fisher's exact test at 0.05 significance level)

\begin{tabular}{|c|c|c|c|}
\hline & $\begin{array}{l}\text { PPMV } \\
\text { owner }\end{array}$ & $\begin{array}{l}\text { PPMV } \\
\text { attendant }\end{array}$ & $P$-value \\
\hline New pill users $(N=184)$ & $(N=150)$ & $(N=34)$ & \\
\hline Prescribed or sold pills & $59(39.3 \%)$ & $16(47.1 \%)$ & 0.443 \\
\hline Referred to higher level & $43(28.7 \%)$ & 13 (38.2\%) & 0.304 \\
\hline $\begin{array}{l}\text { Advised on what to do when } \\
\text { they miss a pill }\end{array}$ & $36(24.0 \%)$ & $8(23.5 \%)$ & 0.575 \\
\hline $\begin{array}{l}\text { Asked if ever used any method of } \\
\text { contraception }\end{array}$ & $50(33.3 \%)$ & 9 (26.5\%) & 0.288 \\
\hline Possible side effects mentioned & $26(17.3 \%)$ & $2(5.9 \%)$ & 0.115 \\
\hline \multirow{2}{*}{$\begin{array}{l}\text { Advised on how to manage } \\
\text { side effects }\end{array}$} & $13(8.7 \%)$ & I (2.9\%) & 0.472 \\
\hline & Male & Female & $P$-value \\
\hline New pill users $(N=184)$ & $(N=165)$ & $(N=19)$ & \\
\hline Prescribed or sold pills & $7 \mathrm{l}(43 \%)$ & $4(21.0 \%)$ & 0.085 \\
\hline Referred to higher level & 49 (30.8\%) & $7(50.0 \%)$ & 0.149 \\
\hline $\begin{array}{l}\text { Advised on what to do when } \\
\text { they miss a pill }\end{array}$ & $44(26.7 \%)$ & $0(0.0 \%)$ & $0.008^{*}$ \\
\hline $\begin{array}{l}\text { Asked if ever used any method of } \\
\text { contraception }\end{array}$ & $55(33.3 \%)$ & $4(21.1 \%)$ & 0.436 \\
\hline Possible side effects mentioned & $28(17.0 \%)$ & $0(0.0 \%)$ & 0.083 \\
\hline \multirow{2}{*}{$\begin{array}{l}\text { Advised on how to manage } \\
\text { side effects }\end{array}$} & $0(0.0 \%)$ & 14 (8.5\%) & 0.368 \\
\hline & English & $\begin{array}{l}\text { Local } \\
\text { languages }\end{array}$ & $P$-value \\
\hline New pill users $(N=169)$ & $(N=108)$ & $(N=6 I)$ & \\
\hline Prescribed or sold pills & $53(49.1 \%)$ & $14(23 \%)$ & $0.00 I^{*}$ \\
\hline Referred to higher level & $28(28.3 \%)$ & $24(40 \%)$ & 0.163 \\
\hline $\begin{array}{l}\text { Advised on what to do when } \\
\text { they miss a pill }\end{array}$ & $31(28.7 \%)$ & $9(14.8 \%)$ & 0.059 \\
\hline $\begin{array}{l}\text { Asked if ever used any method of } \\
\text { contraception }\end{array}$ & 35 (32.4\%) & $13(21.3 \%)$ & 0.156 \\
\hline Possible side effects mentioned & 18 (I6.7\%) & 5 (8.2\%) & 0.162 \\
\hline $\begin{array}{l}\text { Advised on how to manage } \\
\text { side effects }\end{array}$ & $7(6.5)$ & $4(6.6 \%)$ & 1.000 \\
\hline
\end{tabular}

Note: *Significant at $a=0.05$.

Abbreviation: PPMV, proprietary patent medicine vendors.

included nausea (58\%), abdominal pain (46\%), severe headache (44\%), breast pain (37\%), weight gain (26\%), blurred vision (14\%), and irregular menstruation (8\%). However, as shown in Table 2, only 71 of 145 simulated clients (49\%) who presented as dissatisfied users wishing to switch from the pill to other methods were referred to a health facility. Most (79.3\%) were advised to switch to other family planning methods without any questions. Sixteen percent were asked to continue the current oral contraceptive pill type, while $18 \%$ were asked to discontinue the current oral contraceptive pill type, or change the current pill type (11\%) to another type depending on the complaints presented. Ten percent of clients were offered treatment by PPMVs. This offer was made in spite of the fact that offering treatment is
Table 4 Assessment of advice provided to simulated dissatisfied users who wanted to switch method of contraception according to type of PPMV (based on Fisher's exact test at 0.05 significance level)

\begin{tabular}{|c|c|c|c|}
\hline & $\begin{array}{l}\text { PPMV } \\
\text { owner }\end{array}$ & $\begin{array}{l}\text { PPMV } \\
\text { attendant }\end{array}$ & $P$-value \\
\hline $\begin{array}{l}\text { Dissatisfied users wanting to } \\
\text { switch method }(\mathrm{N}=\mid 45)\end{array}$ & $(N=116)$ & $(\mathrm{N}=29)$ & \\
\hline $\begin{array}{l}\text { Advised or referred client to } \\
\text { seek medical help }\end{array}$ & $63(54.3 \%)$ & $8(27.6 \%)$ & $0.012^{*}$ \\
\hline $\begin{array}{l}\text { Change method with no } \\
\text { further action }\end{array}$ & $16(13.8 \%)$ & $5(17.2 \%)$ & 0.768 \\
\hline PPMV prescribes treatment & $9(7.8 \%)$ & $5(17.2 \%)$ & 0.156 \\
\hline $\begin{array}{l}\text { Dissatisfied users wanting to } \\
\text { switch method }(N=\mid 45)\end{array}$ & $(\mathrm{N}=56)$ & $(\mathrm{N}=89)$ & \\
\hline $\begin{array}{l}\text { Advised or referred client to } \\
\text { seek medical help }\end{array}$ & 31 (55.4\%) & $40(44.9 \%)$ & 0.237 \\
\hline $\begin{array}{l}\text { Change method with no further } \\
\text { action }\end{array}$ & $10(17.9 \%)$ & II (I2.4\%) & 0.468 \\
\hline PPMV prescribes treatment & $5(8.9 \%)$ & $9(10.1 \%)$ & 1.000 \\
\hline $\begin{array}{l}\text { Dissatisfied users wanting to } \\
\text { switch method }(N=135)\end{array}$ & $(\mathrm{N}=69)$ & $(\mathrm{N}=66)$ & \\
\hline $\begin{array}{l}\text { Advised or referred client to } \\
\text { seek medical help }\end{array}$ & 39 (56.5\%) & $24(36.4 \%)$ & $0.025^{*}$ \\
\hline $\begin{array}{l}\text { Change method with no further } \\
\text { action }\end{array}$ & $12(17.4 \%)$ & $9(13.6 \%)$ & 0.638 \\
\hline PPMV prescribes treatment & $10(14.5 \%)$ & $4(6.1 \%)$ & 0.158 \\
\hline
\end{tabular}

actually beyond the scope of their practice. Table 4 shows the nature of advice provided by different categories of PPMVs to simulated dissatisfied clients. A significantly higher proportion of PPMV owners (54\%) compared with PPMV attendants $(28 \%)$ advised or referred clients to clinics and hospitals to seek medical help $(P<0.5)$. However, there were no significant differences in proportions who offered to treat simulated clients.

\section{Those who wanted resupply}

Sixty one percent of simulated clients who presented and asked for resupply of pills obtained them with no questions asked. There was no significant difference between the proportion of PPMV owners and PPMV attendants who supplied pills to simulated clients without asking any questions (Table 5). However, the proportion of female PPMVs who supplied pills without question (69\%) was significantly higher than males ( $69 \%$ versus $35 \% ; P<0.05)$.

A critical aspect of the services expected from PPMVs is to refer first time clients who request oral contraceptives to a higher level of care. One of the objectives of the survey was to identify the reasons why PPMVs may not refer new family planning users to family planning clinics and the challenges the PPMVs faced when providing family planning services 
Table 5 Proportion of simulated clients who wanted resupply of pills and were sold pills without questions according to type of PPMV (based on Fisher's exact test at 0.05 significance level)

\begin{tabular}{|c|c|c|c|}
\hline & $\begin{array}{l}\text { PPMV } \\
\text { owner }\end{array}$ & $\begin{array}{l}\text { PPMV } \\
\text { attendant }\end{array}$ & $P$-value \\
\hline Resupply (N=8I) & $(N=58)$ & $(\mathrm{N}=23)$ & \\
\hline \multirow{2}{*}{$\begin{array}{l}\text { Sold pills with no questions } \\
\text { asked }\end{array}$} & $12(20.7 \%)$ & $2(8.7 \%)$ & 0.329 \\
\hline & Male & Female & $P$-value \\
\hline Resupply (N=8I) & $(\mathbf{N}=\mathbf{5 5})$ & $(\mathrm{N}=26)$ & \\
\hline \multirow{2}{*}{$\begin{array}{l}\text { Sold pills with no questions } \\
\text { asked }\end{array}$} & $19(34.5 \%)$ & $18(69.2 \%)$ & $0.004 *$ \\
\hline & English & $\begin{array}{l}\text { Local } \\
\text { Languages }\end{array}$ & $P$-value \\
\hline Resupply (N=76) & $(\mathrm{N}=44)$ & $(\mathrm{N}=32)$ & \\
\hline $\begin{array}{l}\text { Sold pills with no questions } \\
\text { asked }\end{array}$ & $32(72.7 \%)$ & I (3.1\%) & $<0.000$ I* \\
\hline
\end{tabular}

Note: *Significant at $a=0.05$.

Abbreviation: PPMV, proprietary patent medicine vendors.

in their communities. Findings from the qualitative aspect of this study provided further insight. A majority of the trained PPMVs were aware of the situations that necessitated referral of clients who wanted to adopt a family planning method, particularly the oral contraceptive pill. The following quotes reflected their views:

The women are supposed to go to health facilities so that they will be examined in the hospital by professionals to know the method that is medically okay for them. (PPMV, Enugu)

"If it is pills, it means she will come back to us to buy her pills". (PPMV, Enugu)

It was found that only $30 \%$ of first timers were referred. PPMVs who did referrals were of the view that the clients so referred would come back to them to purchase the product. Referral was therefore an advantage to the client and of no loss to the PPMV:

If I refer them after the medical examination and the doctor prescribed the correct one for them, they always come to my place and buy it. They show me the card saying 'see, the one the doctor wrote for me'. (PPMV, Jos)

On the other hand, some of the PPMVs did not refer new clients to appropriate health facilities for fear of losing their clients and reduced sales, seeing as clients referred to hospitals tend to procure the prescribed family planning drugs from the clinics. This was confirmed among many PPMVs. Many conveniently argued that they were unable to distinguish first time (ie, intending users) from existing users. They mentioned that some first timers may come with empty packs obtained from friends and ask to purchase the same brand. This makes it difficult for them to be identified as new users. Secondly, as community members they are sometimes obliged to serve people who come in for resupply on behalf of others. In this way new clients may present themselves as buying for their friends who are known by the PPMV as existing users: "If you explain or refer somebody to a health facility, you won't expect her to come back again". (PPMV, Enugu)

There was evidence that some PPMVs were owned by nurses, practicing or retired, and some other health care professionals. Many of these cadre of health care workers thought they were qualified to prescribe pills from their shops because they work or had worked in the past in hospitals. A nurse PPMV owner argued in this direction as follows:

You see, referring clients to (a) health facility is of no use because I am in a medical department. So it is of no use because when they come to me, that is what (I) am supposed to do for them. (PPMV, Kano)

Some of the PPMVs worked on the maxim of "you hear nothing and you see nothing". They explained that they are in a commercial business and sell what people ask for. Consequently, if someone comes to ask for family planning, given the sensitive nature of contraception, questions are not asked. They feel that, as community members, asking too many questions will only turn people away. The PPMVs mentioned that advice is not given if it is not sought. However, when advice is sought and the client wants PPMVs to recommend a method, it is only then that most will refer to a higher level of care:

If you (client) come to my shop and tell me the name of [the contraceptive method] what you want to buy, I would give you what you want if you don't ask me any questions. But if you come to my shop and say madam, I want advice on this (method), the best thing I should do is to refer to hospital at first. Because if I tell them to take this and it doesn't work with their body system the blame will be on me. (PPMV, Lagos)

As pointed out earlier, while some of the PPMVs reported that the clients usually come back to buy pills from them after they referred them to the hospitals, some felt otherwise. For some in this latter group, the fear that the client would not return to make purchases is the main reason for non-referrals to appropriate health facilities. The findings confirm a study that found that when it comes to contraceptive pills, providers have very little concern for safety procedures such as lack of screening. ${ }^{34}$

Many of those who did not refer mentioned that from experience, women would not visit health facilities even if 
they were referred. The cost of traveling to a health facility to ask for 'ordinary' contraceptive pills was a great burden. The PPMVs presented various reasons why women do not want to visit health facilities on referral. These reasons include, high cost of transportation to the hospital, women's belief that the cost of family planning services at the hospital is high, and an unavailability of health facilities in the communities, especially for clients in rural areas. These reasons were communicated by two PPMVs as follows:

Some (women) after considering the cost of paying transport to the hospital only to get information, they will just buy any contraceptive pill they have heard other women mention such as Duofem. You can refer them but how sure are you that the person really went to the place you referred her to? Some women don't go when you refer them so it is not our fault but the women's fault. (PPMV, Enugu)

The number one thing that will motivate them is if there is a hospital that is very close to them. It will motivate them to want to go to the place, within some minutes they will get there, but if it is far they won't go. (PPMV, Jos)

\section{Discussion}

The mystery client approach has been recommended as a useful research tool to examine and understand client-provider interactions in health delivery. ${ }^{29}$ Mystery or simulated clients are individuals trained to visit service providers as 'clients' to observe the services provided. ${ }^{30,31}$ In Sub-Saharan Africa, this approach has been used in the past 3 decades to assess the quality of care provided by family planning service providers. ${ }^{31,32}$ In recent years, it has been used to assess condom negotiation in Malawi. ${ }^{33}$ In Nigeria, simulated clients have been used to examine counseling and clientprovider interactions in formal family planning settings in 68 pharmaceutical and 85 family planning centres. ${ }^{34}$ Outside Africa, the approach has been used in Peru to assess quality of family planning services including the duration of counseling sessions. ${ }^{35}$ Nearly 3 decades ago, it was utilized to understand barriers to effective family planning in Nepal. ${ }^{36}$

There was evidence that about $70 \%$ of potential new users of oral contraceptives were not referred to the appropriate level of care and that oral contraceptive pills were sold to about $41 \%$ of simulated clients. It was observed that some PPMVs refused to refer new clients because they thought they would lose business. There is a need for training of PPMVs that emphasizes the finding that PPMVs who successfully referred clients to clinics and hospitals often reaped the benefits, as these clients often come back to them to make future purchases. Another challenge mentioned by PPMVs was that they were sometimes unable to distinguish between new and existing users. Although for some PPMVs this was a convenient way to sell products with no questions asked, future training for PPMVs should develop an algorithm that will help PPMVs distinguish potential from existing users and refer the former to appropriate higher levels of care. As the qualitative data showed, some PPMVs felt that, given the sensitive nature of family planning, it was embarrassing to ask women probing questions when women presented to ask for oral contraceptive pills. It is important to emphasize during PPMV training that women who visit PPMV outlets are more likely to be receptive to probing questions and to be more willing to accept the best advice possible if it is provided in an informal fashion. There is evidence in the literature that the reasons why clients prefer obtaining family planning methods from PPMVs could be attributed to 1) the absence of formalities and time wasting at PPMVs prior to being attended, 2) the proximity of the facility to their homes, and 3) the perception that clients will pay more at a health facility. ${ }^{37}$

It was found that some new clients were often asked no questions because many come with the intention to purchase and often mention the name of the contraceptive pill they wish to purchase. Notwithstanding this, PPMV training should include the need for appropriate counseling as this will enable PPMVs to identify those new to family planning and refer them to a health facility. Some PPMVs with some background in health care felt they were qualified to offer contraceptive pills to women on their first visit. PPMV associations need to advise their members to appreciate the fact that even though they may be trained, their outlets are not permitted to offer certain services; in nearly all cases, no questions were asked to rule out contraindications. Only a few clients were actually advised on how to take the pills and what to do when they missed a day's pill. On several grounds the advice given to simulated new pill users fell short of expectations, including in the areas of prescription, referral, and management of side effects. Given that the advice is poor in all areas, training for PPMVs should therefore be comprehensive. There is a need to explore the possibility of offering incentives to PPMVs for every client they refer, as this may offering poor advice which may be beneficial to the PPMVs.

Although some PPMVs referred respondents who presented complications with pills to a health facility, about $50 \%$ did not do so. Some PPMVs simply asked clients to switch from one type of oral contraceptive pill to another or switch to another contraceptive method altogether. Furthermore, one in ten simulated clients who presented with complications 
were offered treatment. This was certainly beyond the PPMVs scope of practice and needs to be addressed in future training. It was found that there was no significant difference in the proportion of PPMV owners and PPMV attendants who offered to treat clients. On the whole, there were no differences between the advice provided by PPMV owners and PPMV attendants. This is worrying given that owners are often considered better educated, well-trained, and belong to associations which strive to improve the services they offer. Subsequent training of PPMVs should continue to include both owners and attendants. Updated training for PPMVs should focus more on the need to refer clients who present with complications to a health facility. PPMVs should also be informed that they are not meant to treat clients with complications or side effects, a task that is evident in the findings, they are currently doing. Among potential new users, the language used in the interaction had one significant effect; compared with interactions in local languages, interactions in English more often resulted in the sale of oral contraceptives. When dealing with clients, particularly new clients, PPMVs should be encouraged to use the local language. This is likely to engender easy understanding and comprehensive counseling, which may in turn encourage PPMVs to avoid selling oral contraceptive pills to new clients without prior visits to appropriate clinics or hospitals. PPMVs have a huge potential in ensuring contraceptive security in Nigeria as a majority of the PPMVs had pills in stock on the day of the survey. Efforts to improve the services they offer to new and existing users of oral contraceptive pills should be an important component of any family planning strategy in Nigeria.

\section{Study limitations}

A limitation of the mystery client methodology is recall bias on the part of the mystery clients - it might have been difficult for them to recall their experiences. Debriefing with the supervisor immediately after interacting with the PPMV was adopted to reduce recall bias. Although the study provides data about the nature of advice provided by PPMVs, the results of the study may not be representative. The study was urban biased as PPMVs in rural areas do not have defined contact addresses that can be easily located.

\section{Conclusion}

PPMVs are crucial in delivering health services in both urban and rural settings in Nigeria. Many tend to offer contraceptive pills, even though they are not authorized to do so. Additionally, some do not refer pill users who present with complications. There is a need to emphasize the need for PPMVs to recognize both their limitations in initiating oral contraceptives and managing clients' complaints arising from use of contraceptives, and in referring such clients to a higher quality of care. Updating training to address the need to refer new family planning clients and clients with complications from pills and other methods of contraception to a health facility, is proposed for PPMVs. An updated training should emphasize that PPMVs should not treat clients with complications or side effects but instead refer them to a health facility. Furthermore, PPMVs should be trained on other methods that a client can use temporarily, such as emergency contraceptive pills, condoms, or Standard Days Method, ${ }^{38}$ prior to pill use. This will assist in addressing the issue of needing an interim or stop gap method to prevent pregnancy for women who live far from a facility or who live in rural areas, prior to commencing an appropriate method by a provider. Communication messages designed to change behavior should be developed to create more awareness among the general population on the affordability of family planning services at the health facilities and the importance of visiting a health facility to see an appropriately trained provider before adopting any family planning method.

\section{Acknowledgment}

Support for our research was made possible by the United States Agency for International Development.

\section{Disclosure}

The authors report no conflicts of interest in this work.

\section{References}

1. Meba K, Dowling P, Antilla J, Cooper R. Liberia: A Contraceptive Security Assessment. Arlington, VA: DELIVER, for the US Agency for International Development; 2007.

2. Akuse RM, Eseigbe EE, Ahmed A, Brieger WR. Patent Medicine Sellers: How Can They Help Control Childhood Malaria? Malar Res Treat. 2010; Article ID 470754: doi:10.4061/2010/470754

3. Snow RW, Peshu N, Forster D, Mwenesi H, Marsh K. The role of shops in the treatment and prevention of childhood malaria on the coast of Kenya. Trans R Soc Trop Med Hyg. 1992;86(3):237-239.

4. van der Geest S. Self-care and the informal sale of drugs in South Cameroon. Soc Sci Med. 1987;25(3):293-305.

5. Sudhinaraset M, Ingram M, Lofthouse HK, Montagu D. What is the role of informal healthcare providers in developing countries? A systematic review. PLoS One. 2013;8(2):e54978.

6. Palafox B, Patouillard E, Tougher S, Goodman C, Hanson K. The private commercial sector distribution chain for antimalarial drugs in Nigeria: Findings from a rapid survey. Available from: http://www.actwatch.info/ downloads/results/98_result_ACTwatch_SC_Nigeria_September_2012. pdf. Accessed May 29, 2013.

7. ACTwatch Group. Outlet Survey Report, Nigeria, 2009 http://www. actwatch.info/sites/default/files/content/outlet-reports/Nigeria $\% 20$ Outlet $\% 20$ Baseline \%2C\%20ACTwatch\%202009.pdf. Accessed February 27, 2014. 
8. Brieger WR, Osamor PE, Salami KK, Oladepo O, Otusanya SA. Interactions between patent medicine vendors and customers in Urban and rural Nigeria. Health Policy Plan. 2004;19(3):177-182.

9. Aguwa EN, Aniebue PN, Obi IE. Management of childhood diarrhoea by patent medicine vendors in Enugu north local government area, South East Nigeria. International Journal of Medicine and Medical Sciences. 2010;2(3):88-93.

10. Erhun WO, Babalola MO, Erhun MO. Drug Regulation and Control in Nigeria: The Challenge of Counterfeit Drugs. Journal of Health and Population in Developing Countries. 2001;4(3):23-34.

11. Salako LA, Brieger WR, Afolabi BM, et al. Treatment of childhood fevers and other illnesses in three rural Nigerian communities. J Trop Pediatr. 2001;47(4):230-238.

12. Enato EF, Okhamafe AO. A survey of anti-malarial activity during pregnancy, and children's malaria care-seeking behaviour in two Nigerian rural communities. Scand J Infect Dis. 2006;38(6-7):474-478.

13. Okeke TA, Uzochukwu BSC, Okafor HU. An indepth study of patent medicine sellers' perspectives on malaria in a rural Nigerian community. Malaria J. 2006;5:97.

14. Berendes S, Adeyemi O, Oladele EA, Oresanya OB, Okoh F, Valadez JJ. Are patent medicine vendors effective agents in malaria control? Using lot quality assurance sampling to assess quality practice in Jigawa, Nigeria. PLOS One. 2012;7(9):e44775.

15. Osamor PE. Health care seeking for hypertension in South West Nigeria Medical Sociology Online. 2011;6:54-69.

16. Ongore D, Nyabola L. Role of shops and shopkeepers in malaria control. East Afr Med J. 1996;73(6):390-394.

17. Werner D, Maxwell J, Thuman C. Where there is no Doctor. A Village Health Care Handbook. Berkeley, CA: Hesperian Health Guides; 1981.

18. Abiola A, Adeyinka B, Alhassan M, et al. A Qualitative Assessment of Medicine Sellers In Igbo-Ora. Project Submitted to the Department of Preventive And Social Medicine. Ibadan, Nigeria: University of Ibadan; 1983.

19. Fassin D. [La vente illicite des medicaments au Senegal: Consequences pour la sante des populations]. Bull Soc Pathol Exot Filiales. 1986;79(4):557-570. French.

20. Mosoru YA, Olowookorun OO, Spiff IA, et al. A Survey of Patent Medicine Stores in Tapa and Ayete. Project Submitted To The Department of Preventive and Social Medicine. Ibadan, Nigeria: University of Ibadan; 1987.

21. Jimmy EO, Achelonu E, Orji S. Antimalarials dispensing pattern by patent medicine dealers in rural settlements in Nigeria. Public Health. 2000;114(4):282-285.

22. Adikwu MU. Sales practices of patent medicine sellers in Nigeria. Health Policy Plan. 1996;11(2):202-205.

23. Abuya T, Fegan G, Rowa Y, et al. Impact of Ministry of Health on private Medicine Retailer knowledge and practices on Anti-malaria treatment in Kenya. Am J Trop Med Hyg. 2009;80(6):905-913.
24. Aniebue PN, Aguwa EN, Obi EI. Universal precautions: Awareness and practice of patent medicines vendors in Enugu metropolis, South East Nigeria. Nig Medical J. 2010;51(1):30-34.

25. National Population Commission [Nigeria], ICF Marco. Nigeria Demographic and Health Survey 2008. Abuja, Nigeria: National Population Commission and ICF Macro; 2009.

26. Monjok E, Smesny A, Ekabua J, Essien, EJ. Contraceptive practices in Nigeria: Literature review and recommendation for future policy decisions. Open Access Journal of Contraception. 2010;2010(1): 9-22.

27. Barnes J, Chandani T, Feeley R. Nigeria Private Sector Health Assessment. Bethesda, MD: Private Sector Partnerships-One project, 2008.

28. BASICS. Improving child health in Tanzania. Arlington, VA: Basic Support for Institutionalizing Child Survival; Available from: http:// www.basics.org/reports/FinalReport/TanzaniaFinalReport_BASICS pdf. Accessed February 26, 2014.

29. Hawkes S, Miller S, Reichenbach L, Nayyar A, Buse K. Antenatal syphilis control: people, programmes, policies and politics. Bull World Health Organ. 2004;82(6):417-423.

30. Hardee K, Janowitz B, Stanback J, Villinski MT. What have we learned from studying changes in service guidelines and practices? Int Fam Plan Persp. 1998;24(2):84-90.

31. Huntington D, Lettenmaier C, Obeng-Quaidoo I. User's perspective of counseling training in Ghana: the "mystery client" trial. Stud Fam Plann. 1990;21(3):171-177.

32. Huntington D, Schuler SR. The simulated client method: evaluating client-provider interactions in family planning clinics. Stud Fam Plann. 1993;24(3):187-193.

33. van den Borne F. Using mystery clients to assess condom negotiation in Malawi: some ethical concerns. Stud Fam Plann. 2007;38(4): 322-330.

34. Saka MJ, Yahaya LA, Saka AO. Counseling and client provider-interactions as related to family planning services in Nigeria. Journal of Education and Practice. 2012;3(5):16-25.

35. León FR, Ríos A, Zumarán A. Training $x$ trainee interactions in a family planning intervention. Evaluation Review. 2005;29:576-590.

36. Schuler SR, McIntosh EN, Goldstein MC, Pande BR. Barriers to effective family planning in Nepal. Stud Fam Plann. 1985;16(5) 260-270.

37. Goodman C, Brieger W, Unwin A, Mills A, Meek S, Greer G. Medicine sellers and malaria treatment in sub-Saharan Africa: what do they do and how can their practice be improved? Am J Trop Med Hyg. 2007; 77(Suppl 6):203-218.

38. Ujuju C, Anyanti J, Adebayo SB, Mohammad O, Oluigbo A, Gofwan A Religion, culture and male involvement in the use of Standard Days Method: Evidence from Enugu and Katsina States of Nigevia. Int Nurs Rev. 2011;58(4):484-490.
Journal of Multidisciplinary Healthcare

\section{Publish your work in this journal}

The Journal of Multidisciplinary Healthcare is an international, peerreviewed open-access journal that aims to represent and publish research in healthcare areas delivered by practitioners of different disciplines. This includes studies and reviews conducted by multidisciplinary teams as well as research which evaluates the results or conduct of such teams or

\section{Dovepress}

healthcare processes in general. The journal covers a wide range of areas and welcomes submission from practitioners at all levels, from all over the world. The manuscript management system is completely online and includes a very quick and fair peer-review system. Visit http://www.dovepress.com/testimonials.php to read real quotes from published authors. 